\title{
Teaching Tools for the Mentor “Trainer” of Professionals Working in Primary Health Care Improving and Growing with Every Challenge
}

\author{
José Luis Turabian* and Benjamin Perez-Franco
}

Health Service of Castilla La Mancha (SESCAM), Toledo, Spain

\begin{abstract}
The effectiveness of mentor derives mainly from his role of "enabler". While experts in the content can be useful, training skills are essential. The main role of the mentor, "trainer" in teaching professionals working in Primary Health Care (nurses, family doctors) is encouraging improvements in the performance of tasks by facilitating the learning process. The mentor does not need to teach a lot, but he has to know how to help them to learn. We present a systematization of trainer teaching tools: 1. Medium environment of learning ("safe", "non-evaluative"); 2 . Self-esteem and self-capacity (start with strengths; the attitude that the other person is able to solve his problems); 3 . Individual interviews in depth: the cycle reflection-action; 4. Meta-learning (learning to learn); 5 . Interview that helps she or he to get to be able (it helps the person to determine what his problem is, why there is a problem, and what solutions exist); and 6. Self-Assessment (the learner becomes more mature, autonomous and responsible).
\end{abstract}

Keywords: Mentors; Learning; Education, Nurses; Family medicine; Methods; Primary health care; Clinical competence

\section{Introduction}

\section{The mentor "trainer"}

Medical education has been discussed since the beginning of the twentieth century, but still it is not clearly defined what its role is, and there are several ways to understand the task of the mentor [1-4]. Mentor is a clinical teacher: an active clinical professional who apply theory to practice. However, the good tutors have to be more than practitioner workforce. Tutor effectiveness derives from a combination of innate ability, expertise in content, teaching experience, personal enthusiasm, and the work of "facilitator". But while experts in content may be useful, facilitation skills are essential $[5,6]$.

"Training" is a teaching-learning process through which allows developing in the learner a better performance in his usual work. "Mentoring" is defined as the deliberate pairing of an expert or experienced professional with a less skilled or less experienced one, with the goal of achieving development of skills in the latter. The effective mentoring does not occur by chance; this is a myth. The tutoring is the process agreed between tutor and learner to interact in a way that facilitates learning, growth, and skills of the learner [7].

Thus, we can speak of a kind of tutor or style of mentor "trainer". The key point to work by the tutor, who makes to be unique the apprentice, is to increase the special strengths of that person. The desire of the mentor in relation with the apprentice "do the same things that the mentor does" is perhaps natural, but it prevents to the student think by himself or take his own responsibilities. A good mentor establishes a free helping relationship with the learner [8-16].

In this context, there is a lack of methodical exposition of teaching tools that the mentor, "Trainer" could use. We present an approach for conceptualization and systematization of these tools and their application in practice for the Primary Health Care professionals (nurses, family doctors and other health professionals).

\section{Discussion}

\section{Teaching tools of trainers}

The Table 1 shows the teaching tools that will be the subject of this text.

\section{Environment of learning}

As the trees that cannot get to grow strong in nutrient poor soils; we cannot develop people in environments that do not include the qualities that you want to achieve. In order to create effective working relationships, we must: 1) To respect and appreciate to the people for what they are, and this is different from friendship or liking or disliking to a person; 2) To demonstrate empathy: one can see things from their point of view; 3) Be honest: be yourself and be honest with yours opinions and feelings; and 4) Do not to rush, go slow; Abraham Lincoln said "Give me six hours to chop down a tree and I will spend the first four sharpening the ax" [17].

Students are not seen as "containers" to be filled with the educational program. Teaching does not simply mean to explain or make practical demonstrations of a skill or procedure. Teaching means creating the conditions for learning, coordinating resources, helping students to reflect on their learning goals, and connect them with the resources and opportunities available. The qualities of a good Primary Health Care professional are not educational objectives specific but an epiphenomenon: a product associated with, or derived of, an educational environment that allows a self-development of the natural tendencies of student. It is not "give excellence" by the mentor to the learner, but to create a learning environment where it develops. The environment of learning must give value to the learner, it must make he feels safe, and create an enabling climate [7,18-20].

\section{Self-Esteem and Self-Capacity}

\section{Starting learning from strengths of the mentor and the learner}

The most important single motivator of human behavior is the

*Corresponding author: Jose L Turabian, Family Doctor, SECAM, Toledo, Spain, Tel: 34925154508; E-mail: jturabianf@hotmail.com

Received: July 20, 2016; Accepted: July 24, 2016; Published: July 31, 2016

Citation: Turabian JL, Perez-Franco B (2016) Teaching Tools for the Mentor "Trainer" of Professionals Working in Primary Health Care Improving and Growing with Every Challenge. J Pat Care 2: 116. doi: 10.4172/2573-4598.1000116

Copyright: (c) 2016 Turabian JL, et al. This is an open-access article distributed under the terms of the Creative Commons Attribution License, which permits unrestricted use, distribution, and reproduction in any medium, provided the original author and source are credited. 


\section{TEACHING TOOLS AND THEIR UNDERLYING CONCEPTS}

1. Learning environment:

"Safe"; Unconditional acceptance; Acknowledging and valuing the expertise of people An appropriate level of autonomy

\section{Self-esteem, auto-empowerment:}

Start With the strengths; The attitude or belief that the other person is able to solve its problems; The Educator does not evaluate or judge from your frame of reference the material that expresses the apprentice

3. Individual interviews in depth:

To set the educational agenda of apprentice, the cycle reflection-action can be used 1.-Scan this scenario

2. Explore the desired scenario

3. Work strategies to move from one to two.

These three steps can be applied to personal, professional or training areas

4. Meta-learning:

Learning to learn; The experience from the experience

\section{Interview for empowerment:}

4 learning stages:

1) Helping the person in order to identify his problem

2) Helping the person to find out why there is a problem

3) Encourage the person to consider as many solutions as possible

4) Encourage the person chooses the most appropriate solution for him

\section{Self-appraisal:}

The evidence that the behavior of the learner changes: he is more mature, autonomous and responsible; less defensive, more firmly based on an objective selfview, with decreased psychological stress, better labor adjustment

\section{PRACTICAL APPLICATIONS AND EXAMPLES}

-Is there a climate of trust; the clinical office (or the class) is a safe place for apprentices; can they take risks or have to auto-protect?

- The tutor, rather than ask himself "How do I see this?", should ask himself "How does see this the apprentice?

Why this career? Tell me about your role in the consultation - what role do you see yourself assuming? What feelings or emotions have you now about this career? Where would you like to be in 5 years? What are your personal strengths?

Why did you decide to learn that? Where did you learn? How did you learn it?

-"The apprentice Anne presented to her tutor John a list of things that drew her attention

- "Why do you think you have these problems, Anne?" Asked John

- "Well ... I think ... I lack experience and knowledge ... on these issues, and so I feel insecure ..." said Anne

- "Mmmm," John said, nodding. "And of all these problems that you have notice, there is one that you think is the main for you right now?, asked John. Etc."

-What am I doing?

-Why am I doing this?

-How am I doing?

-What's next?

-What was good and what improvable?

Table 1: Teaching tools for empowerment.

establishment, maintenance, and increased self-esteem. Protecting this psychological need precedes to the need to take part in an academic activity. Each invitation to learn is an invitation to change, and that can only be done in the presence of someone who makes the learner feel safe and valued. The ability to make people feel safe is a precious talent. By releasing the apprentice of basic concerns about self-esteem, can be devoted to other topics. Prioritizing self-esteem is the key element to motivation and personal development

We all need self-confidence and a positive self-image. The answer to our problems almost always reflects our feelings or perception about ourselves [21-24]. An approach based on deficiencies makes difficult for a person to generate energy, motivation or achieve positive changes [25-28]. A primary task of the tutor is to bring about genuine confidence for the learner can achieve goals. But before that, the tutor has to increase his own self-esteem $[17,19,21]$.

The traditional way to teach anything is to start with the problems or weaknesses. It is much better to start with the strengths of the learner. The educator who aims to train chooses act consistently with the hypothesis that the individual has sufficient capacity to deal constructively all aspects of his life, and he is accepted as a competent person to direct himself. But at the same time, the educator is attentive to the experience to confirm or contradict this hypothesis.

The educator, nor directs, nor is passive; by contrast, the educator who trains the other person is thinking and feeling and exploring with her [22]. The learner, with the aid of mentor, will "speaking/reflect/ responding to himself." When the mentor looks at the behavior of the learner without blame it, or without negative emotions, then the learner can be more objective and can be subject to control and organization. The education by the trainer, in the warmth and safety of the mentorlearner relationship, allows feel to the learner that his experiences are understood and accepted; then he is able to explore new training goals. This relationship provides to the learner that he can perceive security for the first time, and so can understand the meaning and purpose of

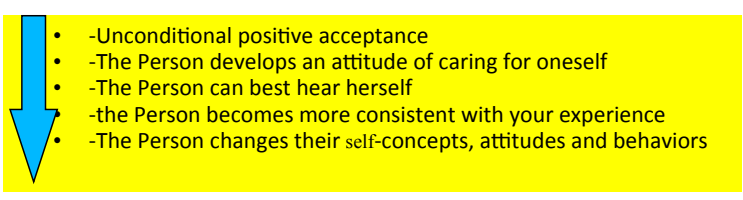

Figure 1: Self-esteem and self-growth.

certain aspects of his behavior and his problems and difficulties. Thus, the learner can himself take a new attitude of accepting and develop himself. The teacher does not evaluate or judge, from his frame of reference, the material that expresses the apprentice. Only if the teacher is free with respect to the results to be obtained the learner can feel the life force, the capacity and potential to make constructive actions (Figure 1) [23,24].

\section{In-depth individual interviews}

Allow defining the educational agenda of the learner, and serve to understand a subject, but also feelings, emotions, attitudes and prejudices concerning him. Do the tutors know, about their apprentices, what are their expectations, what they want to learn, what interests they have, and how can help them? Very few learners reach their rotation with their tutor having clear training agenda. Tutors explore training agreements with personal plans of the learners, giving priority to those important training needs for the learners, from which they can venture into other areas less familiar to them [17].

For this process it is required that the tutor has the necessary skills for that the apprentice articulates his desires and educational needs, and to help him to formulate an educational plan, control the process, and define results. But it is more than that: it is above all; help an adult along an educational process, to achieve a situation of greater personal development. The tutor must point out the contradictions of the learning plan the apprentice if they exist, or suggest more complex alternatives, besides inducing reflection on the action taken. 


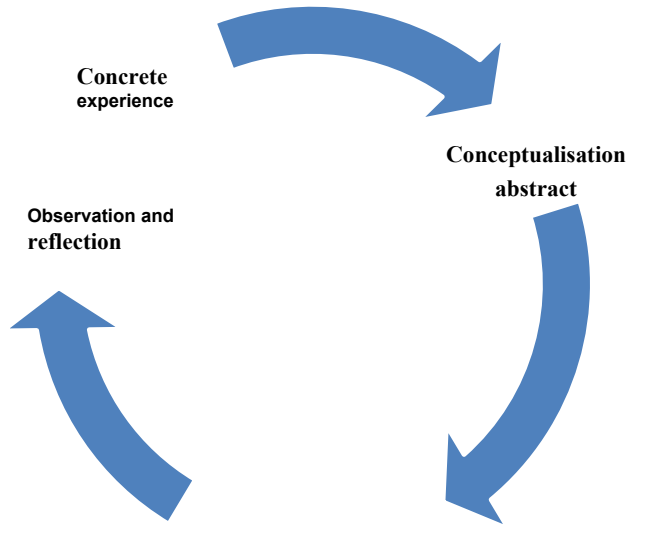

Active experimentation

Figure 2: Cycle action reflection.

The reflection-action cycle is a strategy that helps tutor and student to overcome problems. It also provides the learner an introduction to the comprehensive and relational aspects that are the basis of Primary Health Care (Figure 2). Through in this cycle, from concrete experience, reflection and analysis of experience, identification of theoretical frameworks that explain the experience and finally to its application through experimentation, the student could actively integrating new learning and consequently to consolidate, develop and refine over time, knowledge, skills and attitudes. Failure to complete the cycle leads the student to a loss of learning opportunities [25].

\section{Meta-learning}

Faced with a new learning content that cannot be played by existing knowledge in cognitive structure, the student perceives an imbalance, whose overcoming requires integrating the new content with existing information, leading to review and modify it. The tutor sets the conditions for the student, through his "self-discoverer" activity, perform the review, coordination and modification of knowledge schemes for ensuring learning and rebalancing. Learning is meaningful when new findings are potentially relevant to relate to the cognitive structure of the learner [19].

In the process of mentoring is important to foster critical selfreflection of apprentice, and make him an active agent in his own learning. The experiences of the consultation are the basis for observation and reflection; then they are assimilated into a "theory", from which new implications (behavioral changes...) are deducted; these implications serve as a guide to create new experiences that are tested and so on in the cycle of action and evaluation. This involves training cycle. Two methods are well suited for "trainer" tutors: case studies and role play [17]. These educational methods are powerful vehicles to access the emotional world, and offer the possibility to balance the imagination (the student can enter history as if it were real) and also, to keep certain distance from the clinical case; so the apprentice can project his own experiences to develop his imaginative and empathic abilities, and think and discuss different responses to the case, in a protected environment before being transferred to his daily work.

\section{Interview for training and empowering}

Some people have learned from childhood that they cannot do anything about certain situations in life. Yet another view is that whether people are victims of their own actions or those of others, can and should take an active part in managing their own problems, including finding solutions thereof. Tutors can help learners to change their beliefs and self-negative attitudes and can help to develop more realistic vision about their ability to control situations. Tutors can also help learners to develop the knowledge, skills and resources necessary to achieve success, encouraging them to accept reasonable risks in their development [20].

This training can be produced by a "conversation" (something different from conversation in everyday life). The goal is to help the other thinking about his formative problems, causes, solutions, and finally choose to act. In this conversation there is really no advice: the advice is to help him. This does not mean that the tutor, as a professional, has to accept the decision of apprentice, but it is achieved: 1) Know what is the vision of the student about the problems and solutions; 2) Improve the self-esteem of the student to hear his own version; 3 ) Improve the confidence of the student in the tutor for the same reason; and 4) Propose changes but from the ideas of the student [26].

Effective aid means helping others to help themselves. This means helping learners to rethink their resources for success and failure, and improve their own ability to control the results. This process is not immediate and may take time. Conceptual models provide an overview of the support process, and these include a number of stages, but this does not necessarily imply that the process of helping relationship always improves in an order. The tutor can go back or forward in these stages. According to different authors the logical steps and the aid relationship would be [23,24]: 1 . The clarification of problem; 2 . Consideration of alternatives and possible targets; and 3 . The action of change (Figure 3).

\section{Evaluation}

André Malraux said that "if we really are able to understand, could not judge". Reaching a goal in itself does not have the same value as the experience that can be acquired in the process of solving the obstacles on the way. The process is more rewarding than the victory in itself. When the apprentice is focused on the learning process, his successes and failures are in your goal of self-knowledge and self-development, in day to day [19,27-31].

It is difficult to do evaluation. It is recognized that there are technical barriers to the assessment of individual competition, and to overcome these barriers requires much more research, but even can sometimes be technically impossible to make a valid and proper evaluation [32]. Formative evaluation is more important than summative in adult learning. Formative assessment is the key to independent learning. Summative evaluation is always tentative; we can never be sure of it [19]. In the novel "The Sorcerer's Apprentice" [33], the protagonist is tutored in his training as an apprentice magician. Learning is very hard. At the end of the novel, the apprentice asks the teacher: "Now what do? what is the next part of the course? The master seething with rage as never before had seen him, shouted: -The Course ended! -Finalized? So suddenly? I have approved?

4 stages:

1. Help the students identify areas in which they are competent 2. Help the students identify their strengths and training needs 3. Help the students identify learning resources for their educational goals 4. Help the students to choose alternatives most appropriate learning resources

Figure 3: Interview for empowerment. 
How dare you denigrate this work speaking in terms of passes and fails? No pass or fail. I have revealed the basic principles and I have shown what must seek. The rest is up to you".

In the general trend during the training process by tutor-apprentice relationship, it can be seen that the student moves from focusing on external and past problems, to do so in the present and future and with positive visions. But the most basic change is that it changes his perception of himself toward being accepted and perceived as a person of worth, with capabilities, and autonomous, that can make decisions based on his own experience not in the attitudes and desires of others [5,34-36].

\section{Conclusion}

We have shown some "tools" for use by the tutor in the training of the student. Underlies them that we cannot easily separate between methods and contents: they are closely related [37,38]. In the most training programs for personal growth, increased confidence, and assertiveness, the learning process and conducting participatory activities are priority over content $[19,39]$.

Education has emphasized too much the learning content (considering the mind as an empty vessel to be filled with facts, and based on the accumulation of theoretical information) and has forgotten the value of the learning process directly from the experience. The instructions given to the apprentice externally are not useful to learn. Of course, the learner must know the basic or fundamental aspects, but to go further, apprentices need to learn, but for most of the things they do not need to be taught. The learner has to find his own rhythm, and a way doing things in balance. It is like dancing, like learning to ride a bicycle. We not learned by reading books or listening to instructions (and that goes also for this article!).

The main role of the "trainer" tutor is encouraging improvements in the performance of tasks by facilitating the learning process. No need to teach a lot, but we have to know how to help them learn. This type of teacher is of great value, but he is hard to find. The information is easy. Deep personal reflection is very difficult. Here is the value of being guided through deep personal reflection through the experience. Do not judge the student and help him not judged himself not mean ignore errors apprentice and pretend everything is right. It simply means that we see the events as they are, without putting labels. When we plant a rose seed, we realize that it is small, but do not criticize it. We treat it as a seed, and we water it. When born the first outbreak of the plant from the ground, we do not condemn it for immature and underdeveloped; or we criticize the cocoon because yet it is not open. We accompany the process and care for the plant according to each level of development. The rose is rose from the moment we planted the seed until it dies. Inside it, at all times, is its full potential. In every state, in every moment, it is fine as it is. This task of "gardener" is part of profile of Primary Health Care professional [40].

\section{References}

1. Quintero GA (2014) Medical education and the healthcare system - why does the curriculum need to be reformed? BMC Medicine 12: 213.

2. Sherbino J, Frank JR, Snell L (2014) Defining the key roles and competencies of the clinician-educator of the 21st century: A national mixed-methods study. Acad Med 89: 783-789.

3. Benbassat $\mathrm{J}$ (2016) Role modeling in medical education: The importance of a reflective imitation. Acad Med 89: 550-554

4. Healy AF, Kole JA, Bourne Jr (2014) Training principles to advance expertise Front. Psychol 5: 1-13.
5. Jakubit LD, Eliades AB, Weese MM (2016) Part 1: An overview of mentoring practices and mentoring benefits. Pediatr Nurs 42: 37-38

6. Norman K (2015) How mentors can influence the values, behaviours and attitudes of nursing staff through positive professional socialisation. Nurs Manag (Harrow) 22:33-38.

7. Clark CM (2015) The power and potential of positive mentoring. Nurse Educator 40: $109-110$

8. Kling CM (2015) A conceptual framework for mentoring in a learning organization. Adult Learning 26: 160-166.

9. Scheepers RA, Onyebuchi AA, Jan Heineman M, Lombarts KMJMH (2015) In the eyes of residents good supervisors need to be more than engaged physicians: The relevance of teacher work engagement in residency training Advances in Health Sciences Education 20: 441-55.

10. Burgess A, Goulston K, Oates K (2015) Role modelling of clinical tutors: A focus group study among medical students. BMC Medical Education 15: 17.

11. Detsky AS, Baerlocher MO (2007) JAMA. 297: 2134-2136.

12. Wood DF (2003) Problem based learning. BMJ 2003; 326: 328.

13. Saura Llamas J, Saturno Hernández PJ, Romero Sánchez EB (2008) Estrategias formativas que pueden utilizar los tutores para formar residentes. Archivos en Medicina Familiar 10:84-95.

14. Papp KK, Huang GC, Lauzon Clabo LM, Delva D, Fischer M, et al. (2014) Milestones of critical thinking: A developmental model for medicine and nursing Acad Med 89: 715-720.

15. Turabián JL, Pérez Franco B (2008) Map towards adventure. Aten Primaria 40: 209-216.

16. Myall M, Levet-Jones T, Lathlean J (2008) Mentorship in contemporary practice: The experiences of nursing students and practice mentors. J Clin Nurs 17(14):1834-42.

17. Ruiz Moral R (2009) Educación Médica. Manual práctico para clínicos. Madrid Editorial Médica Panamaericana.

18. Stammen LA, Stalmeijer RE, Paternotte E, Oudkerk Pool A, et al. (2015) Training physicians to provide high-value, cost-conscious care: A systematic review. JAMA 314: 2359 .

19. Vinales JJ (2015) The learning environment and learning styles: A guide for mentors. Br J Nurs 24: 454-457.

20. Jokelainen M, Turunen H, Tossavainen K, Jamookeeah D, Coco K (2011) A systematic review of mentoring nursing students in clinical placements. $J$ Clin Nurs 20: 2854-2867.

21. Jnah AJ, Robinson CB (2015) Mentoring and self-efficacy: Implications for the neonatal nurse practitioner workforce. Adv Neonatal Care 15: E3-11.

22. Gallwey WT (1979) The inner game of golf. London: Pan Books.

23. Rogers CR (1961) On becoming a person. Boston: Houghton Mifflin Company.

24. Rogers CR (1995) A way of being. New York: Houghton Mifflin Company.

25. Mamede S, Schmidt HG (2004) The structure of reflective practice in medicine. Med Educ 38: 1302.

26. Duffy K (2013) Providing constructive feedback to students during mentoring Nurs Stand 27: 50-56.

27. Cooper HN, Goldman KD, Schmalz KJ (2013) Got game? The role of coaches and coaching in improving your career and life "games". Health Promot Pract 14: 801-814.

28. Henry GT, Smith AA, Kershaw DC, Zulli RA (2013) Formative evaluation: Estimating preliminary outcomes and testing rival explanations. Am J Eval 34 465-485.

29. Johnson J, Hall J, Greene JC, Ahn J (2013) Exploring alternative approaches for presenting evaluation results. Am J Eval 34: 486-503.

30. Baldwin LP (2013) Active learning in higher education 14 165-73.

31. Reinke WM, Stormont M, Herman KC, Newcomer L (2014) Using coaching to support teacher implementation of classroom-based interventions. J Behav Educ 23: 150-167

32. Morrison j (2003) $A B C$ of learning and teaching in medicine: Evaluation. BMJ 326: 385 
Citation: Turabian JL, Perez-Franco B (2016) Teaching Tools for the Mentor "Trainer" of Professionals Working in Primary Health Care Improving and Growing with Every Challenge. J Pat Care 2: 116. doi: 10.4172/2573-4598.1000116

Page 5 of 5

33. Shah T (2000) el aprendiz de brujo: Viaje a la India mágica. Barcelona: Alba Editorial. 2000

34. Fischer EA, Javana K, Cunningham T, Wahington M, Mony $P$ et al. (2015) Nurse mentors to advance quality improvement in primary health centers: Lessons from a pilot program in northern Karnataka, India. Glob Health Sci Pract 3: $660-675$

35. Chen Y, Watson R, Hilton A (2016) A review of mentorship measurement tools. Nurse Educ Today 40: 20-28.

36. Cheek RE, Walsh Dotson JA, Ogilvie LA(2016) Continuing education for mentors and a mentoring program for RN-to-BSN students. J Contin Educ Nurs 47: 272-277.
37. Turabián JL, Pérez Franco B (2009) Can fish live out of water? Implications for teaching the biopsychosocial concept in family medicine. Aten Primaria 41 $629-632$

38. Turabián JL, Pérez Franco B (2010) Family medicine clinical sessions: They do exist! Aten Primaria 42: 588-590.

39. Rogers A (1996) Teaching adults. Buckingham: Open University Press.

40. Turabian JL, Perez-Franco B (2016) The family doctors: Images and metaphors of the family doctor to learn family medicine. New York. Nova Publishers. 